\title{
O desempenho das nações em desenvolvimento sustentável: uma análise de conglomerados no environmental performance index
}

Diante da crescente importância conferida aos indicadores de desenvolvimento sustentável e visando a contribuir para a agenda de estudos em desenvolvimento sustentável, o presente trabalho tem como objetivo geral analisar o nível atual de desempenho em desenvolvimento sustentável das nações ao redor do mundo com base nos indicadores que compõem o Environmental Performance Index - EPI. Para tanto, são apresentados, no referencial teórico, a origem, o conceito e as dimensões do desenvolvimento sustentável; a concepção e os principais indicadores de desenvolvimento sustentável; e, por fim, o próprio EPI. Quanto à metodologia, utilizou-se a base de dados do EPI 2014 e aplicou-se o método quantitativo de análise de conglomerados à amostra de 104 dos 178 países que compõem o índice, visto que apenas foram considerados na separação dos grupos aqueles com dados para todas as variáveis utilizadas. Conclui-se, a partir da criação de quatro diferentes grupos de países pela análise de conglomerados, os diferentes níveis de desempenho geral em desenvolvimento sustentável em que se encontram as nações analisadas, além de características dos países que definem o seu desempenho. Por fim, foi possível observar, em cada um dos grupos formados, pontos críticos de avanço em políticas públicas em prol do desenvolvimento sustentável destas nações.

Palavras-chave: Desenvolvimento sustentável; Indicadores de desenvolvimento sustentável; Environmental Performance Index; Análise de conglomerados.

\section{The performance of nations in sustainable development: an analysis of conglomerates in environmental performance index}

In view of the growing importance given to sustainable development indicators and aiming to contribute to the sustainable development studies' agenda, this paper aims to analyze nations' current level of sustainable development performance based on the indicators that compose the Environmental Performance Index - EPI. For this purpose, the theoretical background presents origin, concepts and dimensions of sustainable development; the conception and the most important sustainable development indicators; and, ultimately, the EPI. Regarding methodology, the EPI 2014 database was used and the cluster analysis method was applied to the sample of 104 out of the 178 countries that compose this index, since only countries with data for all indicators used were included in the clusters formation. It was possible to observe the different current levels of nations' general performance in sustainable development by studying the four groups created by cluster analysis, besides the characteristics of the nations that define their performance. Finally, it was possible to observe in each of the groups formed critical points of advancement in public policies for the sustainable development of these nations.

Keywords: Sustainable development; Sustainable development indicators; Environmental Performance Index; Cluster analysis.

Topic: Gestão Ambiental e da Biodiversidade

Reviewed anonymously in the process of blind peer

Roberta Pacheco Gomes

Universidade Federal do Ceará, Brasil

http://lattes.cnpq.br/1525184655625021

robertapachecogomes@gmail.com

Diego de Queiroz Machado

Universidade Federal do Ceará, Brasil

http://lattes.cnpq.br/6926348689036257

diegomachado@ufc.br

\section{Márcia Zabdiele Moreira}

Universidade Federal do Ceará, Brasil

http://lattes.cnpq.br/6888372972174358

marciazabdiele@ufc.br
Received: 28/01/2017

Approved: 29/03/2017

Carlos Manta Pinto de Araújo

Universidade Federal do Ceará, Brasil

http://lattes.cnpq.br/2668062673601276

manta@ufc.br
Referencing this:

GOMES, P. R.; MACHADO, Q. D.; MOREIRA, Z. M.; ARAÚJO, P. M. C.. O desempenho das nações em desenvolvimento sustentável: uma análise de conglomerados no environmental performance index. Revista Brasileira de Administração Científica, v.8, n.1, p.327-342, 2017. DOI: http://doi.org/10.6008/SPC2179-684X.2017.001.0024 


\section{INTRODUÇÃO}

Visto que o Relatório Our Commom Future definiu e popularizou o desenvolvimento sustentável, conseguiu estabelecer objetivos estratégicos e tratou as principais preocupações globais que careciam de um novo paradigma de desenvolvimento, houve espaço para que este movimento ganhasse força. Conforme Barbieri et al. (2010), o desenvolvimento sustentável vem provando ser um dos movimentos sociais mais importantes deste início de século e milênio.

São incontáveis as iniciativas relacionadas com o tema. Grandes empresas desenvolvem seus projetos globais com orientação sustentável permeando toda a organização, buscando boa performance econômica, social e ambiental. Cartas de princípios e diretrizes de ação foram elaboradas e subscritas por diversos Governos nacionais como as Metas do Milênio, os Objetivos de Desenvolvimento sustentável e o Acordo de Paris, evidenciando ser o movimento social que movimentou mais chefes de Estado até hoje.

Nesse contexto, os indicadores de desenvolvimento sustentável funcionariam como uma ferramenta de tomada de decisão direcionada por informações, de aplicação efetiva de recursos crescentemente escassos, de mitigação de riscos decorrentes do insuficiente gerenciamento ambiental, e do cometimento de tornar o desenvolvimento sustentável um tema central na agenda de todas as nações. Assim, devido à crescente importância conferida aos indicadores de desenvolvimento sustentável, alguns estudos destinamse a explicar a importância, a evolução e os principais indicadores de desenvolvimento sustentável, bem como pontuar quais deles são mais reconhecidos enquanto ferramenta de tomada de decisões, além da comparação entre suas metodologias e que tipo de contribuição e aplicabilidade possuem em cada contexto.

Nesse sentido, vale pontuar os trabalhos de Siche et al. (2007), Bellen (2004), Rabelo et al. (2007) e Veiga (2009). Adicionalmente, fazem jus ao destaque os estudos dedicados ao desenvolvimento de novas metodologias de índices de desenvolvimento sustentável: Wackernagel et al. (1996), Hardi et al. (2000), dentre outros.

Como outros índices e indicadores de desenvolvimento sustentável, o Environmental Performance Index (EPI) nasceu do reconhecimento de que a formulação de políticas ambientais muitas vezes carece de rigor científico, principalmente, quantitativo. Atualmente o EPI consiste num índice usado para classificar o desempenho dos países nas questões ambientais de maior prioridade em duas dimensões (objetivos das políticas): saúde humana e vitalidade dos ecossistemas. O EPI entende que a conservação dos recursos naturais e o desenvolvimento sustentável caminham juntos, pois a preservação ambiental reflete-se em bem-estar, efetividade da economia, segurança alimentar e estabilidade social, ou seja, no próprio futuro da humanidade (HSU, 2016; WWF, 2014).

Visando contribuir para a agenda de estudos em desenvolvimento sustentável, o presente trabalho justifica-se por realizar uma análise de desempenho em desenvolvimento sustentável pautada pela característica dos países, tendo como base o EPI, posto que não foi encontrado empenho semelhante nas principais fontes eletrônicas de pesquisa acadêmica. Seu objetivo geral, portanto, consiste em analisar o nível atual de desempenho em desenvolvimento sustentável das nações com base nos indicadores que compõem o EPI. 
Desse modo, espera-se que essa análise apresente contribuições aos governos ao apontar quais políticas públicas estão sendo efetivas e as que devem melhorar; à sociedade, que interpreta sobre quais esferas deve-se concentrar sua cobrança por políticas públicas; às empresas, ao pontuar quais países são mais desenvolvidos em termos ambientais e podem corroborar com os objetivos estratégicos de uma gestão empresarial sustentável. Adicionalmente, visa-se contribuir para a agenda acadêmica no tópico de indicadores de desenvolvimento sustentável, visto que não foram encontrados estudos com a mesma abordagem de conglomerados para identificar características de desenvolvimento sustentável dos países.

\section{REVISÃO TEÓRICA}

\section{Indicadores de desenvolvimento sustentável}

Durante a World Conference on Environment and Development (WCED) em 1992 a ONU destacou o importante papel que os indicadores teriam em auxiliar países a tomar decisões racionais e embasadas no que tange o desenvolvimento sustentável. Assim, neste mesmo ano, um movimento internacional liderado pela Commission on Sustainable Development (CSD) da Organização das Nações Unidas (ONU) foi inaugurado, buscando construir indicadores de sustentabilidade. A proposta do movimento consistia em definir padrões sustentáveis de desenvolvimento que considerassem aspectos ambientais, econômicos, sociais, éticos e culturais para a tomada de decisão. Para atingir essa padronização, pontuou-se a necessidade de elaborar indicadores que mensurassem e avaliassem as organizações e os países em estudo, considerando todos esses aspectos (ONU, 2007; SICHE et al., 2007; VEIGA, 2007).

Por entender que indicadores possuem diversas funções, mostrando o caminho para melhor tomada de decisão e ações mais efetivas ao simplificar, clarificar e representar informação agregada, incorporando conhecimentos das ciências materiais e sociais em unidades de informação, a ONU (2007) define como indicadores de desenvolvimento sustentável (IDS) aqueles que contribuem para mensurar e calibrar o progresso rumo aos objetivos de desenvolvimento sustentável, sinalizando previamente revezes econômicos, sociais e ambientais, além de comunicar ideias, pensamentos e valores deste conteúdo.

Os primeiros portfólios de indicadores de desenvolvimento sustentável foram desenvolvidos entre 1994 e 2001 pela CSD, constituindo as bases de elaboração e implementação dos indicadores sustentáveis de cada nação. Como resultado dessa tarefa, em 1996, a CSD publicou o primeiro documento intitulado 'Indicadores de desenvolvimento sustentável: marco e metodologias' no qual continham 143 indicadores. Destes, apenas 57 foram levados adiante de forma a possuírem fichas metodológicas e diretrizes de utilização. O segundo relatório desse programa de trabalho foi publicado em 2001, estando atualmente na sua terceira versão, do ano 2007 (ONU, 2007; VEIGA, 2007).

A título de exemplo da representatividade desses indicadores para os países, Veiga (2007) acrescenta que foram essenciais para que o Instituto Brasileiro de Geografia e Estatística (IBGE) desenvolvesse e publicasse, em 2002, os primeiros indicadores de desenvolvimento sustentável do Brasil. Esse trabalho contemplava 17 indicadores fundamentais abrangendo cinco temas essenciais - atmosfera; terra; oceanos, mares e áreas costeiras; biodiversidade; e saneamento. 
A publicação do ano de 2002 lançou para debate o trabalho pioneiro de elaboração dos indicadores de desenvolvimento sustentável para o Brasil e provocou o intercâmbio de ideias, buscando alcançar o público não especializado. As edições de 2004, 2008, 2010 e 2012 ampliaram e aprimoraram o rol de indicadores e contribuições aos tomadores de decisões ao apresentar um panorama abrangente dos principais temas relacionados ao desenvolvimento sustentável no Brasil. O relatório de Indicadores de Desenvolvimento Sustentável Brasil 2015 já contemplava 63 indicadores em 15 categorias das quatro dimensões propostas na Agenda 21 - Ambiental, Social, Econômica e Institucional (IBGE, 2015).

Bell et al. (2001) entende que todo o esforço acerca da mensuração desses indicadores resultou, por muito tempo, apenas em números que não são largamente operacionalizados para influenciar ou mudar decisões de legisladores ou gestores. Adicionam, ainda, que os indicadores de desenvolvimento sustentável são mais amplamente utilizados por cientistas e planejadores sociais e naturais, necessitando-se uma abordagem mais voltada ao mercado e políticas públicas. Sugerem, para tanto, a inclusão do ponto de vista dos stakeholders dessas esferas, para torná-los mais abertos e participativos.

Desse modo, conforme Rabelo et al. (2007), no mundo, atualmente, existem diversas ferramentas de mensuração do desenvolvimento sustentável. Cada uma dessas metodologias trabalha com conceitos específicos de desenvolvimento sustentável, não necessariamente o mais famoso do Relatório Brundtland. Estima-se cerca de 559 índices já desenvolvidos sobre o tema (RABELO et al., 2007).

Contribui Siche et al. (2007) que tentativas interessantes no desenvolvimento de índices para avaliar a sustentabilidade de países foram publicadas em importantes revistas internacionais. Entretanto, esses trabalhos não alcançaram a popularização necessária entre os stakeholders da sustentabilidade e, mesmo, entre a comunidade científica, devido ao elevado nível de manipulação de dados, exigindo muito tempo, grande conhecimento do método e de como obter os dados primários, ponderação dos dados e mudança de unidades.

Veiga (2009) defende, então, que atualmente existem quatro índices de sustentabilidade ambiental com ampla visibilidade global: dois do WWF - Living Planet Index (LPI) e Ecological Footprint (EF) - e dois do WEF - Environmental Sustainability Index (ESI) e o Environmental Performance Index (EPI). Siche et al. (2007) afunilam mais essa lista, indicando que a comunidade científica considera o EF e o ESI como os de maior impacto na avaliação da sustentabilidade de países por gerarem grandes discussões e por serem amplamente utilizados no mundo todo.

\section{Environmental Performance Index (EPI)}

O EPI foi apresentado pela primeira vez em 2002 ao Fórum Econômico Mundial por um grupo de trabalho formado por pesquisadores das universidades de Yale e Columbia. Como outros índices e indicadores, o EPI nasceu do reconhecimento de que a formulação de políticas ambientais muitas vezes carece de rigor científico, principalmente, quantitativo. As 7 Metas do Milênio publicadas em 2000 na Agenda 21, para assegurar a sustentabilidade global, não possuíam alvos relevantes e específicos. De modo que o EPI 
resultou das críticas que foram dirigidas à dimensão ambiental das Metas do Milênio, tentando preencher essa vacância (VEIGA, 2009; YALE UNIVERSITY, 2016).

O índice constituiu uma abordagem quantitativa pioneira de avaliação de desempenho ambiental de políticas públicas, buscando em alguma medida abranger também o impacto social (VEIGA, 2009). Durante os 15 anos de existência do índice, resultando na publicação de 10 relatórios, os grupos desenvolvedores do EPI vêm buscando se adaptar continuamente aos novos eventos globais, tecnologias emergentes e desenvolvimentos políticos para que o índice permaneça relevante no contexto de evolução do panorama político internacional (YALE UNIVERSITY, 2016).

O EPI visa suprir a elevada demanda dos Governos, pesquisadores e ativistas por indicadores de desempenho ambiental científicos e robustos impulsionada por: reconhecimento dos benefícios da tomada de decisão baseada em dados; pressão constante sobre os governos para investir efetivamente seus limitados recursos; preocupação crescente com os resultados da má gestão de riscos ambientais; compromisso generalizado para tornar a sustentabilidade um princípio operacional central da agenda internacional de desenvolvimento; rápida difusão de estratégias de sustentabilidade no setor corporativo. Por mais que abranja preocupações de variados públicos, é notório o foco do EPI em servir dados ambientais organizados, compreensíveis e relevantes aos decisores políticos, na intenção de incentivar as nações a competir sobre o avanço das políticas para o desenvolvimento sustentável (HSU et al., 2016; VEIGA, 2009).

Conforme Hsu (2016), os indicadores que formam o EPI são baseados em uma metodologia de "proximidade ao alvo", que identifica quão próximo está cada país do alvo de determinada política, conferindo nota de 0 a 100. De modo geral, os alvos são benchmarks de alta performance definidos primordialmente por metas de políticas internacionais ou nacionais ou por princípios científicos, podendo ser também delineados pelos países com melhor performance. Esses dois grandes acordos políticos sobre o meio ambiente - os ODS e Acordo de Paris - auxiliam na formação de alvos para os indicadores EPI.

Para criar o EPI, conjuntos de dados brutos são padronizados de acordo com a população, área, PIB, dentre outras unidades de medida comuns. Posteriormente, na fase de agregação dos dados, realizam-se transformações estatísticas para assegurar o mínimo de desvios. De modo que, ao final do processo, as bases de dados brutas são transformadas em indicadores de desempenho comparáveis. Uma vez que a base utilizada para os objetivos desse trabalho será a de 2014, o quadro 1 dispõe resumidamente sobre a descrição de cada variável e como se agregam em indicadores e dimensões para formar o índice EPI.

Conforme Hsu (2016), o valor do EPI não reside apenas na sua capacidade de se manter sempre atualizado e na classificação geral entre países. Consiste primordialmente nas métricas repensadas e redesenhadas a cada edição, de forma a constituir uma ferramenta de diagnóstico de fraquezas e eficiências para os países. A estrutura do EPI permite, ainda, a realização de análises temporais e comparativas. Ou seja, possibilita os países comparar o seu desempenho com o dos demais, e, através da análise de dados de séries temporais, observar seu desempenho ao longo do tempo. 
Quadro 1: Composição do EPI.

\begin{tabular}{|c|c|c|c|c|}
\hline & $\begin{array}{l}\text { Dimensão } \\
\text { (Objetivo) }\end{array}$ & Indicador & $\begin{array}{l}\text { Sub indicador } \\
\text { (Variáveis) }\end{array}$ & Explicação \\
\hline \multirow{20}{*}{ 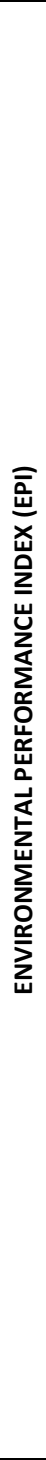 } & \multirow{6}{*}{ 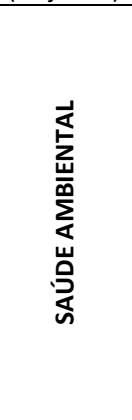 } & Impacto à saúde & Mortalidade infantil & Probabilidade de óbito entre as idades de 1 e 5 anos. \\
\hline & & \multirow{3}{*}{ Qualidade do Ar } & Qualidade do Ar Caseiro & $\begin{array}{l}\text { \% da população utilizando combustíveis sólidos como fonte primária } \\
\text { para cozinhar. }\end{array}$ \\
\hline & & & $\begin{array}{l}\text { Poluição do Ar - Média de } \\
\text { exposição à PM2.5 (partículas } \\
\text { poluentes) }\end{array}$ & $\begin{array}{l}\text { Nível médio de exposição da população a concentrações de } \\
\text { partículas PM2.5 (média de } 3 \text { anos). }\end{array}$ \\
\hline & & & $\begin{array}{l}\text { Poluição do Ar - Excesso de PM2.5 } \\
\text { (partículas poluentes) }\end{array}$ & $\begin{array}{l}\text { Proporção da população exposta à poluição acima do nível permitido } \\
(10,15,25,35 \text { microgramas/m3) }\end{array}$ \\
\hline & & \multirow{2}{*}{$\begin{array}{l}\text { Água e } \\
\text { Saneamento } \\
\text { básico }\end{array}$} & Acesso à água potável & \% da população com acesso à fonte de água potável \\
\hline & & & Acesso à saneamento básico & \% da população com acesso à saneamento básico de qualidade \\
\hline & \multirow{14}{*}{ 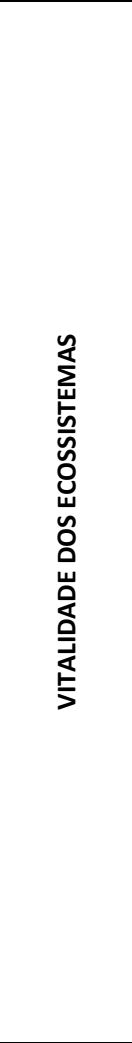 } & $\begin{array}{l}\text { Recursos } \\
\text { Hídricos }\end{array}$ & Tratamento de água & $\begin{array}{l}\text { Nível de tratamento de águas residuais ponderado pela taxa de } \\
\text { tratamento de águas residuais. }\end{array}$ \\
\hline & & \multirow[t]{2}{*}{ Agricultura } & Subsídios à agricultura & $\begin{array}{l}\text { Preço do produto no mercado doméstico + qualquer subsídio a } \\
\text { produtos direto - preço na fronteira, expressos como porcentagem } \\
\text { do preço da fronteira (ajustando custos e transporte e diferenças de } \\
\text { qualidade) }\end{array}$ \\
\hline & & & Regulação de pesticidas & $\begin{array}{l}\text { Quanto os países assinaram a Convenção de Estocolmo em permitir, } \\
\text { restringir ou banir os "dirty dozen" Contaminantes Orgânicos } \\
\text { Persistentes, comumemente, pesticidas agrícolas. }\end{array}$ \\
\hline & & Florestas & Mudança na cobertura florestal & $\begin{array}{l}\text { (Perda florestal) - (ganho florestal > 50\% na cobertura de árvores), } \\
\text { comparada ao nível de } 2000 .\end{array}$ \\
\hline & & \multirow[t]{2}{*}{ Pescas } & $\begin{array}{l}\text { Pressão de pesca à plataforma } \\
\text { costeira }\end{array}$ & Toneladas ao cubo de pesca com redes, dividido pela área da ZEE \\
\hline & & & Estoques de Pesca & $\begin{array}{l}\text { \% de estoques de pesca extremamente explorados e devastados da } \\
\text { ZEE. }\end{array}$ \\
\hline & & \multirow{4}{*}{$\begin{array}{l}\text { Biodiversidade e } \\
\text { Habitat }\end{array}$} & $\begin{array}{l}\text { Áreas terrestres protegidas (peso: } \\
\text { bioma nacional) }\end{array}$ & $\begin{array}{l}\text { \% protegida de área de bioma terrestre, relativa à área de bioma } \\
\text { nacional. }\end{array}$ \\
\hline & & & $\begin{array}{l}\text { Áreas terrestres protegidas (peso: } \\
\text { bioma global) }\end{array}$ & $\begin{array}{l}\text { \% protegida de área de bioma terrestre, relativa à área de bioma } \\
\text { global. }\end{array}$ \\
\hline & & & Áreas marinhas protegidas & \% protegida de área marinha, relativa à ZEE. \\
\hline & & & Proteção à habitat crítico & $\begin{array}{l}\text { \% de locais de habitats críticos protegidos, designados pela Aliança } \\
\text { para Zero Instinção }\end{array}$ \\
\hline & & \multirow{4}{*}{ Clima e Energia } & $\begin{array}{l}\text { Tendência em intensidade de } \\
\text { carbono }\end{array}$ & Mudança na emissão de CO2 por unidade do PIB entre 1990 a 2010. \\
\hline & & & $\begin{array}{l}\text { Mudança na tendência em } \\
\text { intensidade de carbono }\end{array}$ & $\begin{array}{l}\text { Mudança na emissão de CO2 por unidade do PIB entre } 1990 \text { a } 2000 \text { e } \\
2000 \text { a } 2010 .\end{array}$ \\
\hline & & & $\begin{array}{l}\text { Tendência da emissão de CO2 por } \\
\text { KWH }\end{array}$ & $\begin{array}{l}\text { Mudanças na emissão de CO2 para geração de energia elétrica e } \\
\text { para produção de calor. }\end{array}$ \\
\hline & & & Acesso à energia elétrica & $\begin{array}{l}\text { \% da população com acesso à energia elétrica (não utilizado para o } \\
\text { cálculo do } \mathrm{EPI} \text { ). }\end{array}$ \\
\hline
\end{tabular}

Fonte: Yale University (2014).

\section{METODOLOGIA}

Com o objetivo de analisar o nível atual de desempenho em desenvolvimento sustentável das nações ao redor do mundo com base nos indicadores que compõem o EPI, o presente trabalho faz uso da abordagem quantitativa, com análise de dados secundários oriundos do banco de dados do Environmental Performance Index. A base de dados escolhida foi a do ano de 2014, visto que a organização disponibiliza em seu website a 'friendly version', uma versão simplificada e compilada dos dados coletados entre os países para compor o índice, compatível com a confiabilidade que se pretende na coleta e tratamento dos dados desse estudo. 0 EPI foi calculado no ano de 2014 para 178 países, os quais compõem a população da análise quantitativa.

No intuito de agrupar os 178 objetos, visando possibilitar uma análise comparativa dos países com base nos seus indicadores que compõem o EPI, foi utilizada a análise de conglomerados ou cluster, que possui como vantagem a redução da dimensionalidade dos dados com base em uma técnica estatística multivariada de classificação (HAIR et al., 2009). Pohlmann (2012) acrescenta que desta primeira decorre outra vantagem: 
identificação de relações entre os objetos, que não poderiam ser obtidas com base em observações individuais.

Para Hair et al. (2009) a "análise de cluster é um grupo de técnicas multivariadas cujo principal objetivo é agrupar objetos a partir de suas características". Os grupos ou conglomerados tendem a ser homogêneos, de modo que os objetos que os compõem são semelhantes entre si, porém diferentes dos demais objetos dos outros conglomerados. Como softwares de auxílio à pesquisa foram utilizados o IBM SPSS (versão 21) para análise estatística e consequente separação dos países em conglomerados e o Microsoft Excel (versão 2012) para organização dos dados e construção de tabelas e gráficos como suporte à análise.

\section{RESULTADOS E DISCUSSÃO}

No intuito de possibilitar uma descrição taxonômica dos países analisados, utilizando-se as informações da base de dados de 2014 do EPI, iniciou-se a análise estatística com a verificação dos pressupostos que atendem e validam a técnica de análise de conglomerados: ausência de multicolinearidade e representatividade da amostra (POHLMANN, 2012).

Para verificação do primeiro pressuposto, a ausência de multicolinearidade entre as variáveis selecionadas, realizou-se a análise de correlação entre todas as 9 variáveis - indicadores do EPI - cujos coeficientes são apresentados na tabela 1Tabela . Para garantir a ausência de correlação entre as variáveis, quanto ao coeficiente de Pearson, Machado et al. (2015) recomenda o descarte de variáveis com coeficientes maiores que 0,7. A partir da análise da matriz de correlação entre as variáveis, pode-se constatar que o indicador Água e Saneamento Básico apresentou correlação forte com dois outros indicadores: Impactos à Saúde e Recursos Hídricos. Dessa forma, será excluído para efeito de construção de grupos. A correlação é significativa no nível 0,01 ( 2 extremidades) e no nível 0,05 (2 extremidades).

Tabela 1: Matriz de correlações entre as variáveis (Coeficiente de Pearson).

\begin{tabular}{|c|c|c|c|c|c|c|c|c|c|c|c|}
\hline & & & $\begin{array}{l}\text { SA- } \\
\text { Impactc }\end{array}$ & $\begin{array}{l}\text { SA - } \\
\text { Qualidade }\end{array}$ & \begin{tabular}{|l|} 
SA - Água e \\
Saneamento
\end{tabular} & $\begin{array}{l}\text { VE - } \\
\text { Recursos }\end{array}$ & $\begin{array}{l}\text { VE - } \\
\text { Agricul }\end{array}$ & VE - & VE - & 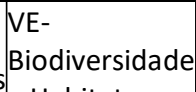 & $\begin{array}{l}\text { VE - } \\
\text { Clima e }\end{array}$ \\
\hline & & & à Saúde & do $\mathrm{Ar}$ & Básico & Hídricos & & & & e Habitat & Energia \\
\hline \multirow{7}{*}{ 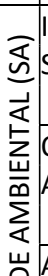 } & \multirow{3}{*}{$\begin{array}{l}\text { Impacto à } \\
\text { Saúde }\end{array}$} & Correlação de Pearson & 1 & ,383 & 870 & ,658 &,- 056 & ,231 &,- 079 & ,184 & ,188 \\
\hline & & Sig. ( 2 extremidades) & & ,000 &, 000 & ,000 & ,457 & ,007 & ,367 & 014 & 033 \\
\hline & & $\mathrm{N}$ & 178 & 178 & 178 & 178 & 178 & 137 & 134 & 178 & 129 \\
\hline & \multirow{3}{*}{$\begin{array}{l}\text { Qualidade do } \\
\text { Ar }\end{array}$} & Correlação de Pearson & , 383 & 1 & ,391 & ,283 &,- 066 & ,116 & ,142 & ,064 &,- 159 \\
\hline & & Sig. ( 2 extremidades) & ,000 & & ,000 & ,000 & 381 & ,175 & ,101 & ,394 & ,072 \\
\hline & & $\mathrm{N}$ & 178 & 178 & 178 & 178 & 178 & 137 & 134 & 178 & 129 \\
\hline \multirow{3}{*}{\multicolumn{2}{|c|}{\begin{tabular}{|l}
$\begin{array}{l}\text { Água e } \\
\text { Saneamento } \\
\text { Básico }\end{array}$ \\
\end{tabular}}} & Correlação de Pearson & 870 & ,391 & 1 & ,738 &,- 095 & ,279 &,- 156 & ,161 & ,206 \\
\hline & & Sig. ( 2 extremidades) & ,000 & ,000 & & ,000 & ,208 & ,001 & ,073 & 031 & ,019 \\
\hline & & $\mathrm{N}$ & 178 & 178 & 178 & 178 & 178 & 137 & 134 & 178 & 129 \\
\hline \multirow{3}{*}{ 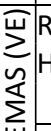 } & \multirow{3}{*}{$\begin{array}{l}\text { Recursos } \\
\text { Hídricos }\end{array}$} & Correlação de Pearson & ,658 & ,283 & ,738 & 1 &,- 130 & ,118 &,- 194 & 177 & ,357 \\
\hline & & Sig. ( 2 extremidades) &, 000 &, 000 &, 000 & & ,083 & ,169 & 025 & 018 & ,000 \\
\hline & & $\mathrm{N}$ & 178 & 178 & 178 & 178 & 178 & 137 & 134 & 178 & 129 \\
\hline \multirow{3}{*}{ 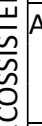 } & Agricultura & Correlação de Pearson &,- 056 &,- 066 &,- 095 &,- 130 & 1 &,- 027 &,- 156 &,- 031 & ,070 \\
\hline & & Sig. ( 2 extremidades) & ,457 & ,381 & ,208 & 083 & & ,757 & ,071 & ,678 & ,429 \\
\hline & & $\mathrm{N}$ & 178 & 178 & 178 & 178 & 178 & 137 & 134 & 178 & 129 \\
\hline \multirow{6}{*}{ 焉 } & \multirow{3}{*}{ Florestas } & Correlação de Pearson & ,231 & ,116 & ,279 & 118 &,- 027 & 1 &,- 037 &,- 314 &,- 045 \\
\hline & & Sig. ( 2 extremidades) & 007 & ,175 & 001 & 169 & ,757 & & ,711 & ,000 & 649 \\
\hline & & $\mathrm{N}$ & 137 & 137 & 137 & 137 & 137 & 137 & 103 & 137 & 104 \\
\hline & \multirow[t]{3}{*}{ Pescas } & Correlação de Pearson &,- 079 & ,142 &,- 156 &,- 194 &,- 156 &,- 037 & 1 & ,053 &,- 160 \\
\hline & & Sig. ( 2 extremidades) & ,367 & 101 & ,073 & 025 & 071 & 711 & & ,540 & 104 \\
\hline & & $N$ & 134 & 134 & 134 & 134 & 134 & 103 & 134 & 134 & 105 \\
\hline
\end{tabular}




\begin{tabular}{|l|l|c|c|c|c|c|c|c|c|c|}
\hline \multirow{3}{*}{$\begin{array}{l}\text { Biodiversidade } \\
\text { e Habitat }\end{array}$} & Correlação de Pearson &, 184 &, 064 &, 161 &, 177 &,- 031 &,- 314 &, 053 & 1 &, 102 \\
\cline { 2 - 11 } & Sig. (2 extremidades) &, 014 &, 394 &, 031 &, 018 &, 678 &, 000 &, 540 & &, 248 \\
\cline { 2 - 11 } & $\mathrm{N}$ & 178 & 178 & 178 & 178 & 178 & 137 & 134 & 178 & 129 \\
\hline $\begin{array}{l}\text { Clima e } \\
\text { Energia }\end{array}$ & Correlação de Pearson &, 188 &,- 159 &, 206 &, 357 &, 070 &,- 045 &,- 160 &, 102 & 1 \\
\cline { 2 - 11 } & Sig. (2 extremidades) &, 033 &, 072 &, 019 &, 000 &, 429 &, 649 &, 104 &, 248 & 129 \\
\cline { 2 - 10 } & $\mathrm{N}$ & 129 & 129 & 129 & 129 & 129 & 104 & 105 & 129 \\
\hline
\end{tabular}

Adicionalmente, para testar a construção dos clusters a partir da análise dos nove indicadores, realizou-se a análise de variância (ANOVA), disposta na tabela 2. Vale mencionar que esse procedimento não possui como objetivo neste trabalho verificar a heterogenia dos grupos, mas identificar se os oito indicadores (variáveis) restantes permitiriam a separação dos grupos e quais seriam significativos neste processo.

Tabela 2: Análise de variância ANOVA.

\begin{tabular}{|l|c|c|c|c|c|c|}
\hline \multirow{2}{*}{} & \multicolumn{2}{|c|}{ Cluster } & \multicolumn{2}{c|}{ Erro } & \multirow{2}{*}{ Z } \\
\cline { 2 - 5 } & Quadrado Médio & Df & Quadrado Médio & Df & \\
\hline SA - Impacto à saúde & 5358,989 & 3 & 243,716 & 80 & 21,989 &, 000 \\
\hline SA - Qualidade do Ar & 452,915 & 3 & 269,927 & 80 & 1,678 &, 178 \\
\hline SA - Água e Saneamento Básico & 13272,944 & 3 & 313,501 & 80 & 42,338 &, 000 \\
\hline VE - Recursos Hídricos & 26086,453 & 3 & 230,632 & 80 & 113,108 &, 000 \\
\hline VE - Agricultura & 537,543 & 3 & 380,710 & 80 & 1,412 &, 245 \\
\hline VE - Florestas & 18910,383 & 3 & 282,765 & 80 & 66,877 &, 000 \\
\hline VE - Pescas & 228,373 & 3 & 187,762 & 80 & 1,216 &, 309 \\
\hline VE - Biodiversidade e Habitat & 2992,039 & 3 & 426,536 & 80 & 7,015 &, 000 \\
\hline VE - Clima e Energia & 1132,747 & 3 & 292,544 & 80 & 3,872 &, 012 \\
\hline
\end{tabular}

Conforme Machado et al. (2015), essa identificação é feita a partir dos valores de sig., que devem ser menores que 0,05 (sig $<0,05)$. Do estudo da tabela 2 percebe-se que os indicadores Qualidade do $\mathrm{Ar}$, Agricultura e Pescas não atendem à condição anterior, devendo ser desconsiderados, restando cinco variáveis para aplicação da técnica de conglomerados: Impactos sobre a saúde, Recursos Hídricos, Florestas, Biodiversidade e Habitat e Clima e Energia.

Refazendo a análise de variância (ANOVA) apenas com os indicadores restantes, todos apresentaram um coeficiente de significância menor que 0,05 , conforme mostra a tabela 3Tabela . Confirmando, assim, que os cinco indicadores supracitados são relevantes para a formação dos grupos, com nível de significância de 5\%. Além disso, segundo Machado et al. (2015) afirma que a utilização da ANOVA permite classificar as variáveis pela sua importância no processo de separação, o maior valor estatístico de $Z$ indica maior influência na separação dos grupos. Ou seja, Recursos Hídricos $(Z=104,262)$ é o indicador de maior impacto na separação dos grupos, seguido por Florestas $(Z=84,467)$. Em contrapartida, o indicador que exerceu mínima influencia na separação dos grupos foi Clima e Energia $(Z=4,895)$.

Destaca-se que os testes ' $\mathrm{F}$ ' devem ser usados apenas para finalidades descritivas porque os clusters foram escolhidos para maximizar as diferenças entre os casos em clusters diferentes. Os níveis de significância observados não estão corrigidos para isso e, dessa forma, não podem ser interpretados como testes da hipótese de que as médias de cluster são iguais.

Tabela 3: Análise de variância ANOVA com indicadores restantes.

\begin{tabular}{|l|c|c|c|c|c|c|}
\hline \multirow{2}{*}{} & \multicolumn{2}{|c|}{ Cluster } & \multicolumn{2}{c|}{ Erro } & \multirow{2}{*}{ Z } & Sig. \\
\cline { 2 - 6 } & Quadrado Médio & Df & Quadrado Médio & Df & 33,035 &, 000 \\
\hline SA - Impacto à saúde & 7212,745 & 3 & 218,338 & 100 & 33,03 \\
\hline VE - Recursos Hídricos & 30140,795 & 3 & 289,086 & 100 & 104,262 &, 000 \\
\hline
\end{tabular}


GOMES, P. R.; MACHADO, Q. D.; MOREIRA, Z. M.; ARAÚJO, P. M. C.

\begin{tabular}{|l|c|c|c|c|c|c|}
\hline VE - Florestas & 24534,844 & 3 & 290,465 & 100 & 84,467 &, 000 \\
\hline VE - Biodiversidade e Habitat & 10002,989 & 3 & 390,089 & 100 & 25,643 &, 000 \\
\hline VE - Clima e Energia & 1397,693 & 3 & 285,522 & 100 & 4,895 &, 003 \\
\hline
\end{tabular}

Para garantir a confiabilidade da amostra, essa se compõe apenas de países que possuem dados para todos os cinco indicadores que serão utilizados para separação dos grupos, constituindo uma amostra de 104 dos 178 países para os quais foram calculados o EPI em 2014. Conforme Pohlmann (2012) "a lógica, o senso comum ou um julgamento equilibrado podem ser usados na seleção de uma amostra que seja representativa." Dessa forma, pode-se inferir que a amostra utilizada nesta pesquisa é representativa da população, por seguir um critério racional de exclusão dos países que não possuem dados para todas as variáveis, cumprindo o segundo pressuposto necessário à análise de conglomerados.

\section{Análise de Conglomerados nos Países}

Como algoritmo de agrupamento, utilizou-se o método não hierárquico de agrupamento K-médias (K-means). Conforme Machado et al. (2015), a metodologia é aconselhada para grandes conjuntos de observações. Acrescenta Pohlmann (2012) que o pesquisador possui liberdade para a escolha da quantidade de grupos, sendo para este estudo arbitrado a separação em quatro clusters. O quadro 2 apresenta o resultado da divisão dos 104 países da amostra em quatro grupos.

De posse dos quatro grupos, cabe uma análise de características comuns aos seus objetos que podem justificar suas performances nos indicadores. Uma vez que o viés de caracterização dos países é seu desempenho em desenvolvimento sustentável, centra-se esta investigação em aspectos econômicos, sociais e ambientais.

Quadro 2: Classificação dos países em grupos.

\begin{tabular}{|c|c|c|c|}
\hline Grupo 1: 21 países & Grupo 2: 22 países & Grupo 3: 33 países & Grupo 4: 28 países \\
\hline $\begin{array}{ll}\text { - } & \text { Armênia } \\
\text { - } & \text { Bósnia e Herzegovina } \\
\text { - } & \text { Bulgária } \\
\text { - } & \text { Crole } \\
\text { - } & \text { Cuba } \\
\text { - } & \text { Geórgia } \\
\text { - } & \text { Hungria } \\
\text { - } & \text { Irã } \\
\text { - } & \text { Irlanda } \\
\text { - } & \text { Cazaquistão } \\
\text { - } & \text { Líbano } \\
\text { - } & \text { Ilhas Maurício } \\
\text { - } & \text { Moldávia } \\
\text { - } & \text { Montenegro } \\
\text { - } & \text { Marrocos } \\
\text { - } & \text { Nova Zelândia } \\
\text { - } & \text { Sérvia } \\
\text { - } & \text { África do Sul } \\
\text { - } & \text { Tunísia } \\
\text { - } & \text { Uruguai }\end{array}$ & 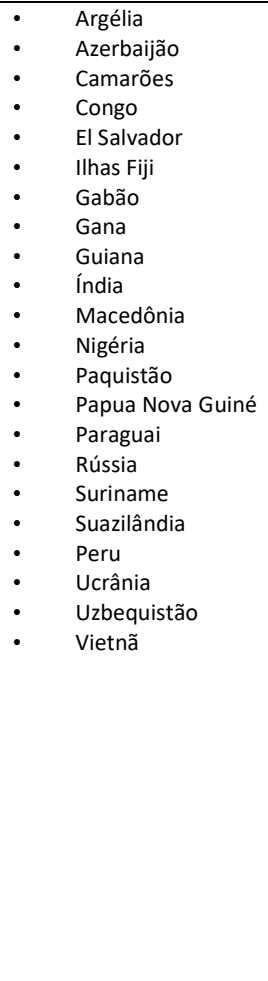 & 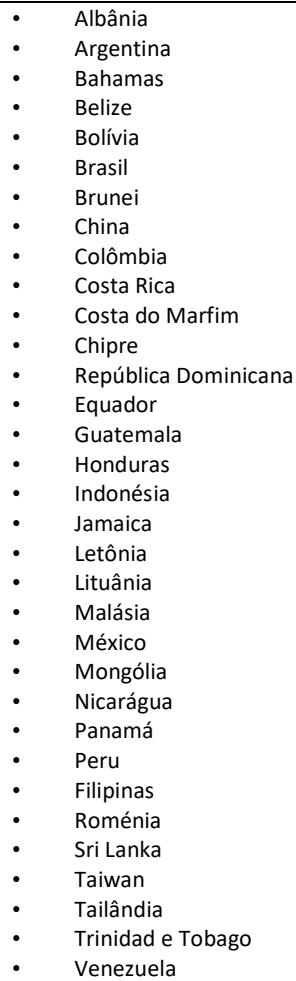 & $\begin{array}{ll}\text { - } & \text { Austrália } \\
\text { - } & \text { Áustria } \\
\text { - } & \text { Bielorrússia } \\
\text { - } & \text { Canadgá } \\
\text { - } & \text { República Tcheca } \\
\text { - } & \text { Dinamarca } \\
\text { - } & \text { Estônia } \\
\text { - } & \text { Finlândia } \\
\text { - } & \text { França } \\
\text { - } & \text { Alemanha } \\
\text { - } & \text { Grécia } \\
\text { - } & \text { Itália } \\
\text { - } & \text { Japão } \\
\text { - } & \text { Luxemburgo } \\
\text { - } & \text { Países Baixos } \\
\text { - } & \text { Noruega } \\
\text { - } & \text { Polônia } \\
\text { - } & \text { Portugal } \\
\text { - } & \text { Eslováquia } \\
\text { - } & \text { Eslovênia } \\
\text { - } & \text { Coreia do Sul } \\
\text { - } & \text { Espanha } \\
\text { - } & \text { Suécia } \\
\text { - } & \text { Síria } \\
\text { - } & \text { Reino Unido } \\
\text { - } & \text { Estados Unidos }\end{array}$ \\
\hline
\end{tabular}


O grupo 1, em geral, é característico de países de nível médio de qualidade de vida, de territórios medianos e de economias em desenvolvimento com algumas chegando à desenvolvidas. Possuem, predominantemente, representantes do leste europeu e do Oriente Médio, com alguns membros na África e com três da América do Sul e Central. Pelas características medianas, não apresentam os melhores ou piores desempenhos nos indicadores, salvo excelente resultado no Florestas, conforme supracitado. Fogem um pouco da caracterização dos demais países a Nova Zelândia e a África do Sul, este último, um dos BRICS.

Já o grupo 2, caracteriza-se por países de baixa qualidade de vida e desenvolvimento econômico. Merecem destaque os diversos representantes da África subsaariana, da América do Sul e da Costa do Pacífico. Explicando, assim, o fraco desempenho em três indicadores. Vale ainda mencionar alguns representantes Asiáticos e do Oriente Médio. Neste grupo, há a presença de dois países do BRICS, Índia e Rússia.

O grupo 3, provavelmente por conter mais elementos, é menos hegemônico. Um fator que aproxima diversos representantes é o clima quente e úmido, reforçando o melhor desempenho no indicador Biodiversidade e Habitat. Quanto à economia, são predominantemente em desenvolvimento, com algumas economias subdesenvolvidas. O grupo heterogêneo possui diversos representantes da América do Sul e Central e da Ásia, com quantidade relevante de países africanos. De forma análoga, merecem destaque dois componentes do BRICS, China e Brasil.

Por fim, o grupo 4 é reconhecidamente de países desenvolvidos, com as melhores qualidades de vida do mundo. Os representantes desse grupo protagonizam as iniciativas mundiais em proteção ambiental, de modo a justificar o melhor desempenho em três indicadores. $\mathrm{O}$ grupo possui diversos representantes da União Europeia, que padroniza as ações de seus membros.

Vale ressaltar, ainda, que todos os países do G7, sendo eles: Estados Unidos, Alemanha, Canadá, França, Itália, Japão e Reino Unido, as sete economias mais avançadas do mundo, pertencem a este grupo, caracterizando $25 \%$ do total de objetos. Juntas, concentram cerca de $50 \%$ do PIB mundial acompanhadas de IDHs extremamente elevados (LAUB et al., 2015). Uma vez caracterizados os grupos de países, vale a inclusão de todos os nove indicadores e do próprio índice EPI para uma análise mais abrangente. Para tanto, os quatro grupos formados são explorados com base na média de todos os indicadores, conforme mostra a seguir a tabela 4 e o Gráfico 1.

Relativo ao score do EPI, o grupo $4(\mathrm{EPI}=70,63)$ se confirma como o de maior nota seguido pelos grupos 1 (EPI=58,75), próximo do grupo 3 (EPI=52,14) e, por fim o grupo $2(E P I=43,67)$. O ranking entre os grupos de países é compatível com a caracterização econômica, social e ambiental feita anteriormente, validando a melhor média das notas entre o grupo 4, composto de países desenvolvidos, com elevados IDHs e protagonistas nas discussões mundiais em proteção da saúde humana e ambiental, e a pior média das notas no grupo 2, de países subdesenvolvidos e baixo desenvolvimento humano e tecnológico.

Iniciando pela variável Impactos à saúde, que leva em conta, principalmente, a mortalidade infantil probabilidade de óbito entre as idades de 1 e 5 anos - o grupo $1(84,00)$ apresenta melhor desempenho, seguido pelo grupo $4(68,59)$ e grupo $2(56,75)$ cabendo o último lugar ao grupo $3(51,23)$. Mostra-se 
relevante quanto a esse indicador o grupo 1 , de nível médio de qualidade de vida, estar à frente do grupo 4 , dos países mais desenvolvidos, além do fato de que o grupo 2 , que possui inúmeros países de baixa qualidade de vida, inclusive os da África subsaariana, figurar à frente do grupo 3, de composição hegemônica.

Tabela 4: Média dos grupos no EPI e por indicador.

\begin{tabular}{|c|c|c|c|c|c|c|c|c|c|c|}
\hline $\begin{array}{l}\text { Gru } \\
\text { pos }\end{array}$ & $\begin{array}{l}\text { EPI } \\
\text { Scor } \\
\text { e }\end{array}$ & $\begin{array}{l}\text { SA - Impacto } \\
\text { s à saúde }\end{array}$ & $\begin{array}{l}\text { SA - } \\
\text { Qualidade } \\
\text { do Ar }\end{array}$ & $\begin{array}{l}\text { SA - Água e } \\
\text { Saneamento } \\
\text { Básico }\end{array}$ & $\begin{array}{l}\text { VE - } \\
\text { Recursos } \\
\text { Hídricos }\end{array}$ & $\begin{array}{l}\text { VE - } \\
\text { Agricultu } \\
\text { ra }\end{array}$ & $\begin{array}{l}\text { VE - } \\
\text { Floresta } \\
\text { S }\end{array}$ & $\begin{array}{l}\text { VE - } \\
\text { Pescas }\end{array}$ & $\begin{array}{l}\text { SA - } \\
\text { Biodiversidade e } \\
\text { Habitat }\end{array}$ & $\begin{array}{l}\text { VE - Clima e } \\
\text { Energia }\end{array}$ \\
\hline 1 & 58,75 & 84,00 & 86,08 & 69,67 & 27,31 & 74,19 & 92,38 & 14,94 & 42,80 & 47,06 \\
\hline 2 & 43,67 & 56,75 & 76,64 & 35,89 & 10,11 & 71,65 & 39,41 & 22,39 & 41,04 & 49,37 \\
\hline 3 & 52,14 & 51,23 & 48,21 & 42,92 & 42,08 & 47,95 & 41,81 & 49,77 & 61,99 & 45,65 \\
\hline 4 & 70,63 & 68,59 & 64,84 & 61,87 & 56,67 & 51,50 & 48,35 & 53,57 & 67,38 & 61,12 \\
\hline
\end{tabular}

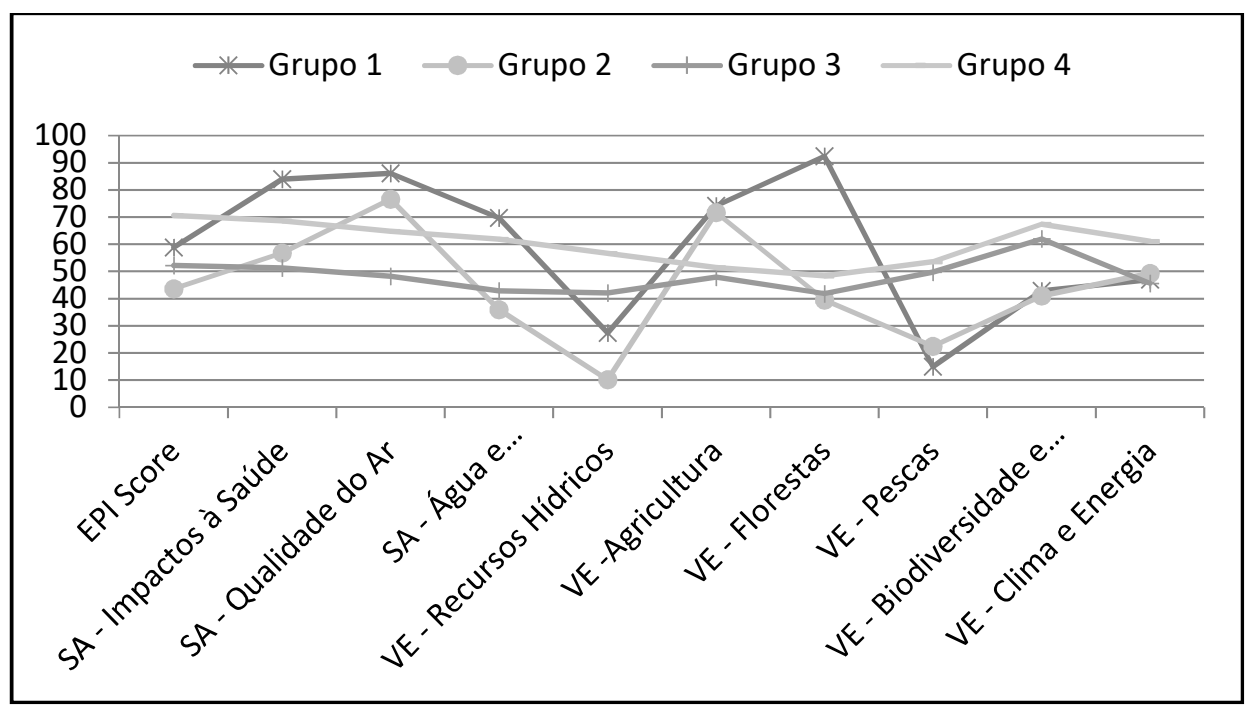

Gráfico 1: Média dos grupos no EPI e por indicador.

Quanto ao indicador Qualidade do Ar, que considera o percentual da população utilizando combustíveis sólidos como fonte primária para cozinhar, a proporção da população exposta à poluição, bem como o nível médio desta exposição, tem como detentor do melhor score o grupo $1(86,08)$, seguido do grupo $2(76,64)$, grupo $4(64,84)$ e, por fim, grupo $3(48,21)$. O desempenho do grupo 1 explica-se pelo nível de atividade industrial dos seus países, que não é comparável com a do grupo 4, das maiores economias. Este último, por mais que possua tecnologias de redução da poluição do ar, possui os países mais industrializados do mundo, inclusive os Estados Unidos. 0 grupo 3, de pior desempenho, também possui industrialização representativa - com destaque para os BRICS China e Brasil - e deve a pior nota ao fato de não possuir as mesmas tecnologias de mitigação de danos ao ar que o grupo 4 . A nota do grupo 2, segunda melhor, narra a industrialização, em geral, incipiente dos seus componentes.

Já o indicador Água e Saneamento Básico refere-se ao percentual da população com acesso à água potável e saneamento básico de qualidade. O score do grupo $1(69,67)$ garante o melhor desempenho, seguido pelo grupo $4(61,87)$, grupo $3(42,92)$ e grupo $2(35,89)$. Nessa variável, faz jus a destaque o grupo 1 , de economias e qualidade de vida mediana, figurar à frente do grupo 4, dos países mais desenvolvidos em economia e qualidade de vida, principalmente pela infraestrutura destes últimos. Entretanto, as características do grupo 2, países de menores economias e piores qualidades de vida, compatibilizam com o pior resultado no indicador. Vale ressaltar a posição muito próxima do grupo 3 em relação ao último 
colocado, justificada pela ausência de infraestrutura e qualidade de vida impostas pela rápida e tardia industrialização de parte dos seus componentes.

O indicador Recursos Hídricos mensura o nível de tratamento de águas residuais. Nesta variável, o grupo $4(56,67)$ garantiu o melhor desempenho, decorrente da cultura e da capacidade tecnológica dos países de reaproveitamento e racionamento de recursos naturais. Vale consideração, pelas questões tecnológicas e socioeconômicas já mencionadas, o fato do grupo $3(42,08)$, de países em desenvolvimento, figurar à frente do grupo 1 (27,31), de países desenvolvidos, além do problema de água potável que alguns representantes deste último grupo enfrenta, principalmente, no Oriente Médio. $O$ último lugar cabe ao grupo $2(10,11)$, realidade compatível com suas características socioeconômicas e tecnológicas. Destaca-se, também, as médias gerais dos grupos muito baixas para esse indicador.

Para o indicador Agricultura, referente ao volume de subsídios à agricultura e à regulamentação quanto ao uso de pesticidas, os grupos aparecem na seguinte ordem: grupo $1(74,19)$, grupo $2(71,65)$, grupo $4(51,50)$ e grupo $3(47,95)$. Neste indicador, merece atenção o fato do grupo 4 figurar somente em terceiro lugar, uma vez que conta com os países - Estados Unidos e União Europeia - que investem pesadamente em subsídios à Agricultura, disputando entre eles diversas causas na Organização Mundial do Comércio. E quanto à regulamentação ao uso de pesticidas, embora os Estados Unidos faça uso em escala, outros países desenvolvidos, principalmente, os europeus, possuem cultura do consumo de produtos mais orgânicos e naturais.

Por sua vez, o indicador Florestas, que mensura a mudança na cobertura florestal comparada aos anos 2000 , tem no grupo $1(92,38)$ um excelente resultado, quando confrontado com os demais, grupo 4 $(48,35)$, grupo $3(41,81)$ e grupo $2(39,41)$. Neste indicador, os piores resultados do grupo 3 e 2 são compatíveis com o fato de possuírem os países com as maiores coberturas florestais do mundo, acompanhadas de regulamentações insipientes de proteção e baixa fiscalização da prática de desmatamento.

Já o indicador Pescas, que mensura a pressão de pesca à plataforma costeira e o percentual de estoques de pesca extremamente explorados e devastados, possui as piores médias de indicadores entre os países, com scores muito baixos. A melhor nota cabe ao grupo $4(53,57)$, seguido dos grupos $3(49,77), 2$ (22,39), 1 (14,94). Assim como o indicador anterior, este possui extrema relação com legislação e fiscalização, merecendo destaque o fato do grupo 1 possuir média de desempenho tão baixa, provavelmente, pela vasta zona costeira dos países e pretensa frouxidão legal e fiscalizatória. Vale destacar, também, o desempenho do grupo 3, bem próximo ao grupo 4.

Quanto ao indicador Biodiversidade e Habitat, que mensura o percentual de áreas terrestres protegidas em relação ao bioma nacional e global, bem como das áreas marinhas protegidas em relação à zona econômica exclusiva e o percentual de proteção à habitats críticos quanto à extinção de espécies, o grupo de melhor média é o $4(67,38)$, próximo do $3(61,99)$, seguido pelo $1(42,80)$, quase empatado com o $2(41,04)$. Bem interligado com os dois indicadores anteriores, relaciona-se, também, com disposições legais e fiscalização, bem como com interesse institucional, principalmente, governamental, em proteção das áreas 
para preservação. Vale ressaltar a nota do grupo 1 , muito próxima do grupo 2 , confirmando mais uma vez 0 pobre desempenho deste em indicadores relacionados à questões legais e fiscalizatórias, colocando-o próximo ao grupo dos países menos desenvolvidos economicamente e em qualidade de vida.

Por fim, o indicador Clima e Energia considera a mudança na tendência de emissão de CO2 por unidade do PIB, bem como esta mudança para geração de energia elétrica e para produção de calor. O grupo $4(61,12)$ possui média bem à frente dos outros grupos indicando uma efetiva tendência das economias mais desenvolvidas em cumprir protocolos e acordos internacionais de redução de emissões de $\mathrm{CO} 2$, às custas de melhorias tecnológicas dos meios de produção. Os outros grupos possuem médias muito próximas nas notas entre os países: grupo $2(49,37)$, grupo $1(47,06)$ e grupo $3(45,65)$. Faz jus a destaque o grupo 2, que em detrimento de suas características socioeconômicas, tecnológicas e regulamentares, foi o segundo grupo nesta variável. Requere mencionar, também, o grupo 3, indicando que as economias de desenvolvimento tardio e acelerado possuem fraco desempenho em relação à evolução nas suas tendências em emissão de carbono.

Em suma, o quadro 3 apresenta as características encontradas em cada um dos grupos de países analisados, pontuando aspectos da economia, desenvolvimento humano, ranking na análise dos indicadores, padrão entre os indicadores, bem como em quais deles os grupos de países tiveram melhor e pior desempenho.

Quadro 3: Perfil dos grupos de países.

\begin{tabular}{|c|c|c|c|c|}
\hline GRUPOS & 1 & 2 & 3 & 4 \\
\hline $\begin{array}{l}\text { Características } \\
\text { econômicas* }\end{array}$ & $\begin{array}{l}\text { Economias em } \\
\text { desenvolvimento }\end{array}$ & $\begin{array}{l}\text { Economias } \\
\text { subdesenvolvidas }\end{array}$ & $\begin{array}{l}\text { Economias em desenvolvimento e } \\
\text { subdesenvolvidas }\end{array}$ & $\begin{array}{l}\text { Economias } \\
\text { desenvolvidas }\end{array}$ \\
\hline $\begin{array}{l}\text { Desenvolvimento } \\
\text { Humano* }\end{array}$ & Médio & Baixo & Médio & Alto \\
\hline $\begin{array}{l}\text { Ranking desempenho } \\
\text { DS }\end{array}$ & 20 & 40 & 30 & 10 \\
\hline $\begin{array}{l}\text { Padrão entre os } \\
\text { indicadores }\end{array}$ & Extremo & Extremo & Linear & Linear \\
\hline Melhor desempenho & $\begin{array}{l}\text { - Impactos à saúde } \\
\text { - Qualidade do Ar } \\
\text { - Água e saneamento } \\
\text { básico } \\
\text { - Agricultura } \\
\text { - Florestas }\end{array}$ & Nenhum & Nenhum & $\begin{array}{l}\text { - Recursos Hídricos } \\
\text { - Pescas } \\
\text { - Biodiversidade e } \\
\text { Habitat } \\
\text { - Clima e energia }\end{array}$ \\
\hline Pior desempenho & - Pescas & $\begin{array}{l}\text { - Água e saneamento } \\
\text { básico } \\
\text { - Recursos Hídricos } \\
\text { - Florestas } \\
\text { - Biodiversidade e } \\
\text { Habitat }\end{array}$ & $\begin{array}{l}\text { - Impactos à saúde } \\
\text { - Qualidade do Ar } \\
\text { - Agricultura } \\
\text { - Clima e Energia }\end{array}$ & Nenhum \\
\hline
\end{tabular}

Legenda: *Predominante

De posse da análise geral dos grupos e pelo resultado comportamento fornecido pelo gráfico 1 , percebe-se que os grupos 4 e 3 possuem desempenhos mais lineares, estando este último, sempre em posição inferior ao primeiro, enquanto os grupos 1 e 2 apresentam performances extremas entre os indicadores, com o grupo 2 figurando majoritariamente, abaixo do grupo 1. Vale ressaltar ainda que os desempenhos negativos do grupo 1 são tão extremos, que conseguem se sobrepor ao melhor desempenho em cinco dos nove indicadores que compõem o EPI. 
Diante da análise das médias dos indicadores para cada grupo de países, nota-se que o desempenho em desenvolvimento sustentável engloba questões muito amplas de uma nação: condições socioeconômicas, tecnologia, investimentos em qualidade de vida, infraestrutura, geografia, cultura, ação de proteção aos recursos naturais, legislação, fiscalização, ambiente institucional, dentre outros. Além disso, é nítido que um grupo de países não possui desempenho homogêneo em todos os indicadores, ou seja, é o pior em uns, melhor em outros, confirmando a complexidade, bem como a relevância que deve ser dispensada ao desenvolvimento com pilares sustentáveis.

\section{CONSIDERAÇÕES FINAIS}

Cumprindo com o objetivo desse trabalho de analisar o nível atual de desempenho em desenvolvimento sustentável das nações com base nos indicadores que compõem o EPI, foi possível observar, a partir dos grupos criados pela análise estatística de conglomerados, os diferentes níveis de desempenho geral em desenvolvimento sustentável em que se encontram os países e como suas características econômicas, sociais e ambientais definem esse nível.

Além disso, esta análise constatou que diversos fatores como tecnologia, investimentos em qualidade de vida, infraestrutura, geografia, cultura, ação de proteção aos recursos naturais, legislação, fiscalização, ambiente institucional, dentre outros, fornecem meios e são essenciais para o bom desempenho em desenvolvimento sustentável. De forma geral, compreendeu-se que o nível de desenvolvimento econômico é determinante ao desempenho em desenvolvimento sustentável, visto que os países desenvolvidos tiveram a melhor performance, os países em desenvolvimento possuem performances medianas, conseguindo pontuar bem em alguns indicadores e mal em outros, enquanto as economias subdesenvolvidas apresentam dificuldade de exercer efetivamente o desenvolvimento sustentável. Ou seja, ao estabelecer um termômetro em desenvolvimento econômico, o desempenho em desenvolvimento sustentável, possui a mesma graduação.

Assim, ao separar as nações em grupos por semelhanças quanto às suas características de desenvolvimento sustentável, foi possível perceber pontos de melhoria em cada grupo de países, abrindo espaço para o avanço de políticas públicas nacionais, além de debates e acordos internacionais de proteção à sociedade e ao ambiente. Confirmando, desse modo, o mérito deste trabalho em esmiuçar um índice de desenvolvimento sustentável em seus indicadores, evidenciando em quais âmbitos os países possuem um bom desempenho para que possam reforçar e confirmar suas ações nessa direção, bem como os ramos de mau desempenho, que merecem foco e iniciativas efetivas.

A caracterização realizada nos quatro grupos de países permite a construção de um quadro geral para melhorias em prol da criação de bases sólidas que permitam o desenvolvimento sustentável. Foi possível perceber, a partir dos dados expostos, quais questões regulatórias, fiscalizatórias, socioeconômicas e de infraestrutura constituem os principais entraves neste processo. Assim, pode-se apontar, por exemplo, uma necessidade dos países do grupo 1 em evoluir nos indicadores que possuem aspectos relacionados à regulamentação e fiscalização, como Pescas, Biodiversidade e Habitat e Clima e Energia. Bem como a 
urgência dos países dos grupos 2 e 3 em agirem em prol da qualidade de vida da população, uma vez que tiveram scores baixos em necessidades básicas de condição humana, representadas nos indicadores Impactos à Saúde e Água e Saneamento Básico. Para o Grupo 4, que possui bom desempenho no geral, cabe a vanguarda das discussões internacionais, bem como do desenvolvimento tecnológico, cultural, institucional e regulamentar necessário rumo ao desenvolvimento sustentável.

Há, contudo, de se ressaltar que a análise de conglomerados possuiu limitações na medida em que só foram utilizadas cinco dos nove indicadores que compõem o EPI, devido à presença de correlação entre as variáveis. Ainda, não se pôde trabalhar com a população de 178 países, pois apenas 104 deles possuíam dados válidos para todas as cinco variáveis de separação dos grupos. Adicionalmente, por se tratar de uma técnica descritiva, a análise de conglomerados não traz respostas conclusivas acerca do fenômeno estudado, demandando estudos posteriores que investiguem mais profundamente as conclusões obtidas por meio da aplicação desta análise. No mais, sendo a composição dos grupos totalmente influenciada pelas variáveis, reconhece-se que a solução obtida é exclusiva para o conjunto utilizado de indicadores.

Dessa forma, este trabalho não elimina a necessidade constante de pesquisas como as tradicionalmente realizadas, que exploram em profundidade as particularidades de cada um desses países, conferindo a devida relevância ao contexto internacional no qual eles se inserem. Uma vez identificados fatores que influenciam no desempenho em desenvolvimento sustentável, sugere-se também estudos que cruzem dados como IDH, PIB, nível de desenvolvimento tecnológico, dentre outros, com os indicadores de desenvolvimento sustentável dos países, no intuito de identificar relações entre essas variáveis. Há também a possibilidade de realização de outra análise de conglomerados considerando os vinte sub-indicadores que compõem o EPI. Por fim, indica-se a realização da mesma análise do presente trabalho, porém com bases de dados de outros anos, permitindo uma comparação interessante entre os resultados em diferentes momentos do tempo.

\section{REFERÊNCIAS}

BARBIERI, J. C.; VASCONCELOS, I. F. G.; ANDREASSI, T.; VASCONCELOS, F. C.. Inovação e Sustentabilidade: Novos modelos e Proposições. Revista de Administração de Empresas, São Paulo, v.50, n.2, p.146-154, 2010.

BELL, S.; MORSE, S.. Breaking through the Glass Ceiling: who really cares about sustainability indicators?. Local Environment, v.6, n.3, p.291-309, 2001.

BELLEN, H. M. V.. Desenvolvimento Sustentável: Uma Descrição das Principais Ferramentas de Avaliação.

Ambiente \& Sociedade, v.7, n.1, p.67-87, 2004.

HAIR, J. F.; BLACK, W. C.; BABIN, B. J.; ANDERSON, R. E.; TATHAM, R. L.. Análise Multivariada de Dados. 6 ed. Porto Alegre: Bookman, 2009.

HSU, A.. 2016 Environmental Performance Index. New Haven: Yale University, 2016.
IBGE. Instituto Brasileiro de Geografia e Estatística. Indicadores de Desenvolvimento Sustentável Brasil 2015 Rio de Janeiro: IBGE, 2015.

LAUB, Z.; MCBRIDE, J.. The Group of Seven (G7). Nova Iorque: Council on Foreing Relations, 2015.

MACHADO, D.; DINIZ, G. M.; OGASAVARA, M. H.; MATOS, F. R. N.. Doing Business: uma análise comparativa das regulamentações no BRICS. Revista de Administração Contemporânea, Rio de Janeiro, v.19, n.3, p.355-373, 2015.

ONU. Organização das Nações Unidas. Indicators of Sustainable Development: Guidelines and Methodologies. Nova York: ONU, 2007.

POHLMANN, M. C.. Análise de Conglomerados. In: CORRAR, L. J.; PAULO, E.; MARIA, D. F. J.. Análise Multivariada. São Paulo: Atlas, 2012. p.324-388. 
RABELO, L. S.; LIMA, P. V. P. S.. Indicadores de Sustentabilidade: a possibilidade da mensuração do desenvolvimento sustentável. REDE: Revista Eletrônica do Prodema, Fortaleza, v.1, n.1, p.55-76, 2007.

SICHE, R.; AGOSTINHO, F.; ORTEGA, E.; ROMEIRO, A.. Índices versus indicadores: precisões conceituais na discussão de sustentabilidade entre países. Ambiente \& Sociedade, Campinas, v.10, n.2, p.137-148, 2007.

VEIGA, J. E. D.. Desenvolvimento sustentável: alternativas e impasses. In: KEINERT, T. M. M.. Organizações sustentáveis: utopias e inovações. São Paulo: Annablume, 2007. p.330.
VEIGA, J. E. D.. Indicadores socioambientais: evolução e perspectivas. Revista de Economia Política, v.29, n.4, p.421435, 2009.

WACKERNAGEL, M.; REES, W. E.. Our Ecological Foot-print: Reducing Human Impact on the Earth. Ottawa: New Society Publishing, 1996.

WWF. World Wide Found for Nature. Living Planet Report 2014. Glad: WWF, 2014

YALE UNIVERSITY. Introduction: Environmental Performance Index. New Haven: Yale University Press, 2016. 